CLINICAL STUDY

\title{
Fertility, sexuality and testicular adrenal rest tumors in adult males with congenital adrenal hyperplasia
}

\author{
Henrik Falhammar $^{1,2}$, Helena Filipsson Nyström ${ }^{5}$, Urban Ekström ${ }^{1,3}$, Seth Granberg ${ }^{4,6}$, Anna Wedell ${ }^{2,7}$ and \\ Marja Thorén ${ }^{1,2}$ \\ Departments of ${ }^{1}$ Endocrinology, Metabolism and Diabetes, D02:04, ${ }^{2}$ Molecular Medicine and Surgery, ${ }^{3}$ Andrology and ${ }^{4}$ Obstetrics and Gynecology, \\ Karolinska Institute, Karolinska University Hospital, SE-171 76 Stockholm, Sweden, ${ }^{5}$ Department of Endocrinology, Sahlgrenska Academy, Sahlgrenska \\ University Hospital, University of Gothenburg, Göteborg, Sweden, ${ }^{6}$ Department of Obstetrics and Gynecology, Akershus University Hospital, Lorenskog, \\ Norway and ${ }^{7}$ Karolinska Institute, Centre for Inherited Metabolic Disorders (CMMS), Karolinska University Hospital, SE-171 76 Stockholm, Sweden \\ (Correspondence should be addressed to H Falhammar at Department of Endocrinology, Metabolism and Diabetes, D02:04, Karolinska Institute, Karolinska \\ University Hospital; Email: henrik.falhammar@ki.se)
}

\begin{abstract}
Objective: Fertility in males with congenital adrenal hyperplasia $(\mathrm{CAH})$ is reported from normal to severely impaired. Therefore, we investigated fertility/fecundity, social/sexual situation, and pituitarygonadal function in $\mathrm{CAH}$ males.

Subjects and methods: The patient cohort comprised 30 males, aged 19-67 years, with 21-hydroxylase deficiency. Their fertility was compared with age-matched national population data. For the evaluation of social/sexual factors and hormone status, age-matched controls were recruited $(n=32)$. Subgroups of different ages $(<30$ years and older) and CYP21A2 genotypes (null (severe salt-wasting (SW)), I2splice (milder SW), and I172N (simple virilizing)) were also studied. Patients underwent testicular ultrasound examination $(n=21)$ and semen analysis $(n=14)$.

Results: Fertility was impaired in $\mathrm{CAH}$ males compared with national data $(0.9 \pm 1.3$ vs $1.8 \pm 0.5$ children/father, $P<0.001)$. There were no major differences in social and sexual factors between patients and controls apart from more fecundity problems, particularly in the I172N group. The patients had lower testosterone/estradiol $\left(\mathrm{E}_{2}\right)$ ratio and inhibin $\mathrm{B}$, and higher $\mathrm{FSH}$. The semen samples were pathological in $43 \%(6 / 14)$ of patients and sperm concentration correlated with inhibin B and FSH. Testicular adrenal rest tumors (TARTs) were found in $86 \%(18 / 21)$. Functional testicular volume correlated positively with the testosterone/ $\mathrm{E}_{2}$ ratio, sperm concentration, and inhibin $\mathrm{B}$. Patients with pathological semen had increased fat mass and indications of increased cardiometabolic risk. Conclusions: Fertility/fecundity was impaired in CAH males. The frequent occurrence of TARTs resulting in testicular insufficiency appears to be the major cause, but other factors such as elevated fat mass may contribute to a low semen quality.
\end{abstract}

European Journal of Endocrinology 166 441-449

\section{Introduction}

Reported fertility in males with congenital adrenal hyperplasia $(\mathrm{CAH})$ has ranged from normal (1) to severely impaired (2). The occurrence of testicular adrenal rest tumors (TARTs) is considered to be the main reason for fertility problems. Their typical location in the rete testis is associated with the risk of obstruction of the seminal ducts, with subsequent permanent testicular damage. Increased adrenal androgens due to not only undertreatment but also overtreatment with glucocorticoids, leading to gonadotropin suppression, may hamper fertility $(3,4)$.

The relative impact of different components involved is not evident from previous studies. One reason may be the different modes of evaluation used. Testicular function has been studied by measuring inhibin B and serum gonadotropin levels, along with semen analysis and/or the number of biological children. TARTs have been diagnosed using palpation, ultrasound, or magnetic resonance imaging $(1,2,4,5,6,7,8,9,10$, $11,12)$.

We have previously shown that reduced fertility in females with $\mathrm{CAH}$ is mainly attributable to social and sexual issues (13), but very little is known about these issues in males with $\mathrm{CAH}$.

Thus, the aim of this study was not only to evaluate fertility, fecundity, and TARTs in adult CAH males, but also to investigate the social and sexual factors of importance for fertility. Moreover, younger and older patients, as well as different CYP21A2 genotypes, were compared to reveal the potential changes associated with age or disease severity. commercial use, distribution, and reproduction in any medium, provided the original work is properly cited. 


\section{Subjects and methods}

\section{Subjects}

CAH males, $\geq 19$ years of age, were mainly recruited from the two participating university hospitals. The diagnosis was confirmed by mutation analyses of the CYP21A2 gene (31 patients) or the HSD3B2 gene (one patient).

The data were divided into subgroups according to age as $<30$ years and older and according to the three most prevalent CYP21A2 mutations as null, I2splice, and I172N. In compound heterozygotes, the mildest mutation defines the genotype group. Null is associated with the salt-wasting (SW) phenotype, I2splice is most often associated with the SW phenotype but some patients may escape SW, and I172N typically leads to simple virilizing (SV) CAH. Matched controls born on the same date as the patients were recruited from the National Population Registry. The only exclusion criterion was severe mental or psychiatric disturbance with inability to consent to the study. Age-matched national fertility data were also used (children/father) (14).

This study was approved by the Ethics Committees of the Karolinska Institute, Stockholm, and the University of Gothenburg, Göteborg, Sweden. All participants gave their written informed consent.

\section{Study protocol}

Patients and controls were examined as outpatients at Karolinska University Hospital (22 patients and 22 controls), Stockholm, or Sahlgrenska University Hospital (ten patients and ten controls), Göteborg, Sweden. Serum and plasma samples were collected in the morning after an overnight fast before morning medication. All participants answered questionnaires concerning social and sexual issues, fertility, and fecundity. Fecundity problems were defined as attempting to become a father for $>1$ year. Patients underwent testicular ultrasound imaging and were also asked to deliver a semen sample. Published data from this cohort on body composition measured by dual-energy X-ray absorptiometry and cardiovascular risk factors (15) were used to evaluate whether differences could be found in these parameters between patients with normal and patients with pathological semen.

\section{Testicular examination}

The testicles were only examined at one of the participating centers. This was done by manual palpation and ultrasound. An orchidometer was used to estimate the volume. The ultrasound examinations were performed by one physician (S Granberg) using a Voluson Expert 730 machine equipped with a
6-16 MHz real-time three-/four-dimensional linear probe (GE Healthcare Austria GmbH \& Co. OG, Zipf, Austria). Total testicular, TART, and functional (total testicular-TART) volumes were estimated using the formula for a prolate ellipsoid (maximal length $\times$ maximal width $\times$ maximal depth $\times 0.523)(16)$.

\section{Semen analysis}

Seminal fluid was collected after 1-4 days of ejaculatory abstinence. The analyses included assessment of semen volume, sperm concentration, total sperm count, motile and immotile spermatozoa, and morphology. Results were evaluated according to the World Health Organization (WHO) standard (17).

\section{Biochemical assays}

Serum testosterone, sex hormone-binding globulin (SHBG), and dried blood spot 17-hydroxyprogesterone (170HP, measured at 0800, 1400, 1900, 0100, and $0600 \mathrm{~h}$ ), and 24-h urinary pregnanetriol were measured as described previously (15). Bioactive testosterone was calculated from total testosterone, SHBG, and albumin (18). Serum FSH, LH, estradiol $\left(\mathrm{E}_{2}\right)$, and total prostate-specific antigen (PSA) and free PSA were measured by fluoroimmunoassay (AutoDelfia, PerkinElmer, Waltham, MA, USA). FSH and LH had normal ranges of 1.0-10 U/l. Serum inhibin B was measured by ELISA (Beckman Coulter, Toronto, ON, Canada; normal range was 25-325 ng/l and detection limit was $10 \mathrm{ng} / \mathrm{l})$. Plasma ACTH was measured on an advantage automatic immune analyzer and plasma renin by immunoradiometric assay (both from Nichols Institute Diagnostics, San Clemente, CA, USA).

\section{Statistical analysis}

SigmaStat for Windows (Jandel Scientific, Erkarath, Germany) was used for data analysis. Results are presented as mean \pm s.D. if not otherwise stated. An unpaired $t$-test was used to compare two groups when values were normally distributed. Otherwise, the Mann-Whitney rank sum test was used and in these cases the median and range were reported. One-way ANOVA was used when comparing three groups with continuous variables and if normally distributed, followed by the post-hoc Bonferroni t-test; otherwise, the Kruskal-Wallis test was performed, followed by the post-hoc Mann-Whitney rank sum test and Dunn's method. $\chi^{2}$ test or Fisher's exact test was used in frequency table calculations. All proportions were calculated discounting missing values. Spearman's correlation coefficient was used for correlation analyses. Statistical significance was set at $P<0.05$ and tendency at 0.05-0.10. 


\section{Results}

\section{Characteristics of the patients and controls}

The characteristics of the patients have been described earlier (15). In brief, 32 males with CAH, aged 19-67 years, were examined. Thirty-one had 21-hydroxylase deficiency. Eighteen had been diagnosed with the SW phenotype (genotype groups: null, $n=7$; I2splice, $n=9$; I172N, $n=1$; and C75R, $n=1$ ). One patient had 3-betahydroxysteroid dehydrogenase (3$\beta$-HSD) type II deficiency (genotype: C75R). Twelve patients had been diagnosed with the SV form (I172N, $n=8$; I2splice, $n=3$; and P453S, $n=1$ ). One SV patient had karyotype 46,XX (I2splice). Two patients had the non-classic (NC) phenotype with normal baseline ACTH levels (mildest mutation V281L and P105L + P453S). The patients with $3 \beta$-HSD deficiency and 46,XX were excluded from further analysis of the data but are separately described at the end of this section. Thus, 30 patients were included in the statistical analysis.

Glucocorticoids were taken by 93\% (28/30) of the patients. One recently diagnosed 29-year-old man (I172N) took no medication and another with the NC phenotype (V281L) only used prednisolone when acutely ill. The most frequently used preparations were prednisolone $(62 \%, 18 / 29)$ and hydrocortisone $(17 \%, 5 / 29)$. The mean dose expressed in glucocorticoid equivalents was $32.7 \pm 12.4 \mathrm{mg}$ using the conversion previously described (19). Urine pregnanetriol and blood $170 \mathrm{HP}$ diurnal curves were similar for the different genotypes and age groups (15).

Most patients $(87 \%, 26 / 30)$ received fludrocortisone, which was also received by most of the SV patients $(82 \%, 9 / 11)$ and one of the NC patients. The SV and NC patients used fludrocortisone to minimize the glucocorticoid dose. None of the CAH males had experienced prostate problems. In the control group, a 67-year-old man had antiandrogen therapy after prostatectomy for cancer and was excluded in all calculations concerning testicular function, a 58-year-old man was operated on for benign prostatic hyperplasia, and a 45-year-old man had recurrent prostatitis.

\section{Fertility, fecundity, and sexuality}

On comparing the number of biological children of $\mathrm{CAH}$ patients with age-matched national data, the fertility was low (in all patients, $0.9 \pm 1.3$ vs $1.8 \pm 0.5$; $<30$ years, $0.1 \pm 0.3$ vs $1.3 \pm 0.4$; $\geq 30$ years, $1.2 \pm 1.4$ vs $2.0 \pm 0.3$; children/father, $P<0.001$ for all comparisons). In patients with classic 21-hydroxylase deficiency, the corresponding frequency was $0.9 \pm 1.3$. The reduction of fertility was similar in the three genotype groups (null, I2splice, and I172N) compared with agematched national data $(P<0.001)$. One $\mathrm{NC}$ man had three while the other had no children. However, compared with our investigated controls, fertility and the age at the time of birth of the first child (not shown) were similar although more patients than controls had experienced fecundity problems (Table 1). Three patients had attempted to father but never succeeded, compared with one control, but one of them fathered a child 1 year after the investigation. The rate of marriage/cohabitation was similar in the entire patient group compared with controls. A propensity to increased frequency of marriage/cohabitation in older compared with younger subjects was only found in controls. A similar percentage of patients and controls had no partner (Table 1). One control had two adopted children.

The age at sexual debut and frequency of intercourse were similar between the groups (not shown), but the lifetime number of partners was lower in the total group of patients and in older patients compared with controls. One control declared that he was homosexual compared with none in the patient group. No bisexuality was reported. As shown in Table 2, there was no difference between the genotype groups regarding fertility, fecundity, and sexuality. However, compared with controls, the null group patients have had fewer partners, fewer I2splice patients were married/cohabitants, and fecundity problems were more common in the $1172 \mathrm{~N}$ group patients.

\section{Biochemical tests}

Inhibin B was lower and FSH higher in all groups of CAH males compared with controls (Tables 1 and 2). The values were negatively associated in the entire patient cohort $(r=-0.514, P<0.001)$. Three patients had subnormal inhibin B and four had elevated FSH concentrations. No differences in LH levels were found. No subject displayed subnormal FSH or LH.

As expected, both older patients and controls had lower bioactive testosterone than the younger ones. An overall tendency to lower bioactive testosterone and higher $\mathrm{E}_{2}$ in patients than in controls resulted in a significant decrease of the testosterone/ $\mathrm{E}_{2}$ ratio in all and older patients, with the latter also having a lower ratio than their younger counterparts (Table 1). SHBG was similar in all groups (not shown). Total PSA and free PSA concentrations were similar in all comparisons (not shown).

\section{Testicular examination}

At manual palpation performed in 70\% (21/30) of patients and controls, smaller testicular volumes were found in patients compared with controls (Table 1). Patients with the null mutation had smaller testicles than those with other genotypes or controls. A unilateral tumor was palpated in one patient and multiple bilateral tumors in another (Table 1). However, with the aid of ultrasound (completed in 70\% (21/30)), $86 \%(18 / 21)$ were shown to have TARTs, which were 


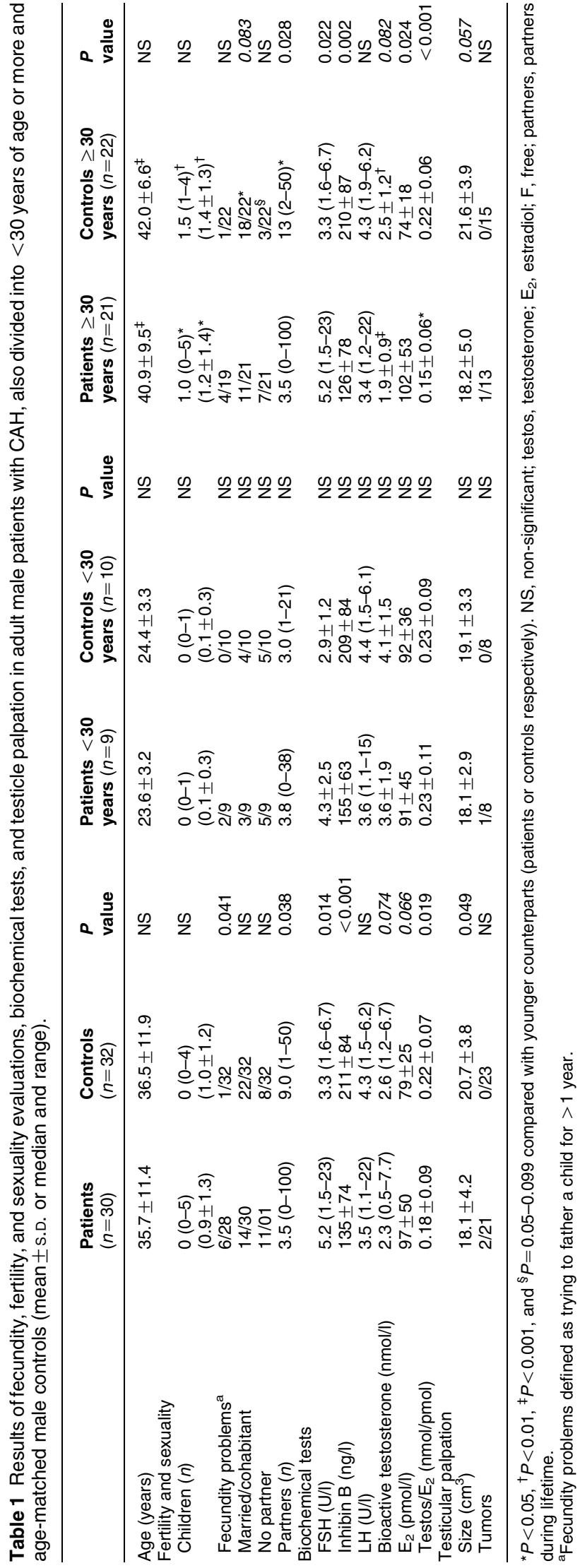

bilateral in $72 \%(13 / 18)$ of cases. An image illustrating a TART from one of the patients is shown in Fig. 1. No significant difference was found in TART frequency and number, total TART volume, or functional testicular volume between genotypes (Table 3). Two patients with genotypes associated with very mild disease (V281L and P105L + P453S) had small TARTs $\left(0.31-0.38 \mathrm{~cm}^{3}\right)$.

Patients with the largest TARTs $(n=8$, volume $>1 \mathrm{~cm}^{3}$ ) had similar age and fat mass but higher lean mass $\left(19.5 \pm 2.4 \mathrm{vs} 16.6 \mathrm{~kg} / \mathrm{m}^{2}, P=0.025\right)$ and shorter height $(162 \pm 8$ vs $173 \pm 6 \mathrm{~cm}, P=0.011)$ than those with no or very small TARTs $\left(n=7\right.$, volume $\left.<0.2 \mathrm{~cm}^{3}\right)$. Poor treatment control, arbitrarily defined as urinary pregnanetriol $\geq 100 \mu \mathrm{mol} / 24 \mathrm{~h}$ and/or a 24 -h median $17 \mathrm{OHP}$ value $\geq 100 \mathrm{nmol} / \mathrm{l}$, was found in three of the eight patients with larger TARTs but in none of those with no or very small TARTs.

Two patients had undergone previous testicular surgery for suspected malignancy. In both cases, the histopathology was interpreted as benign Leydig cell tumors. One 41-year-old SW patient (I2splice) had a testicular tumor extirpated at 12 years of age. He now had one small tumor in each testicle (volume $0.11 \mathrm{~cm}^{3}$ ), normal semen, and two biological children. In a 34-year-old SW patient (I2splice) with two biological children, a tumor was removed before conception. He now showed multiple bilateral tumors. One 23-year-old SV patient (I2splice) with TARTs had been operated on for testicular retention at age 17 . No testicular intervention was reported in any of the controls.

\section{Semen analysis}

Semen for analysis was obtained from 14 of the 30 $\mathrm{CAH}$ males. Fecundity problems tended to be more common in those who delivered a semen sample than in those who declined $(5 / 14$ vs $1 / 16, P=0.072)$. The mean ages were similar $(37.7 \pm 12.7$ vs $35.6 \pm 11.9$ years).

Considering all WHO criteria, six of the 14 semen samples were pathological. The results were similar in younger and older patients (not shown). A lower sperm count, concentration, and motility in $1172 \mathrm{~N}$ compared with the I2splice group did not reach statistical significance in this limited material (Table 3). Only one patient in the null group had an analyzed sample and it was pathological. One 39-yearold patient with SV (I172N) had severe teratozoospermia with impaired motility and a previously performed intracytoplasmic sperm injection (ICSI) resulting in one child.

We found that inhibin B levels, regarded as a marker of spermatogenesis, were negatively correlated to body mass index (BMI; $r=-0.509, P=0.004$ ) in the controls and demonstrated a similar trend in the patients $(r=-0.317, P=0.087)$. Hence, body 


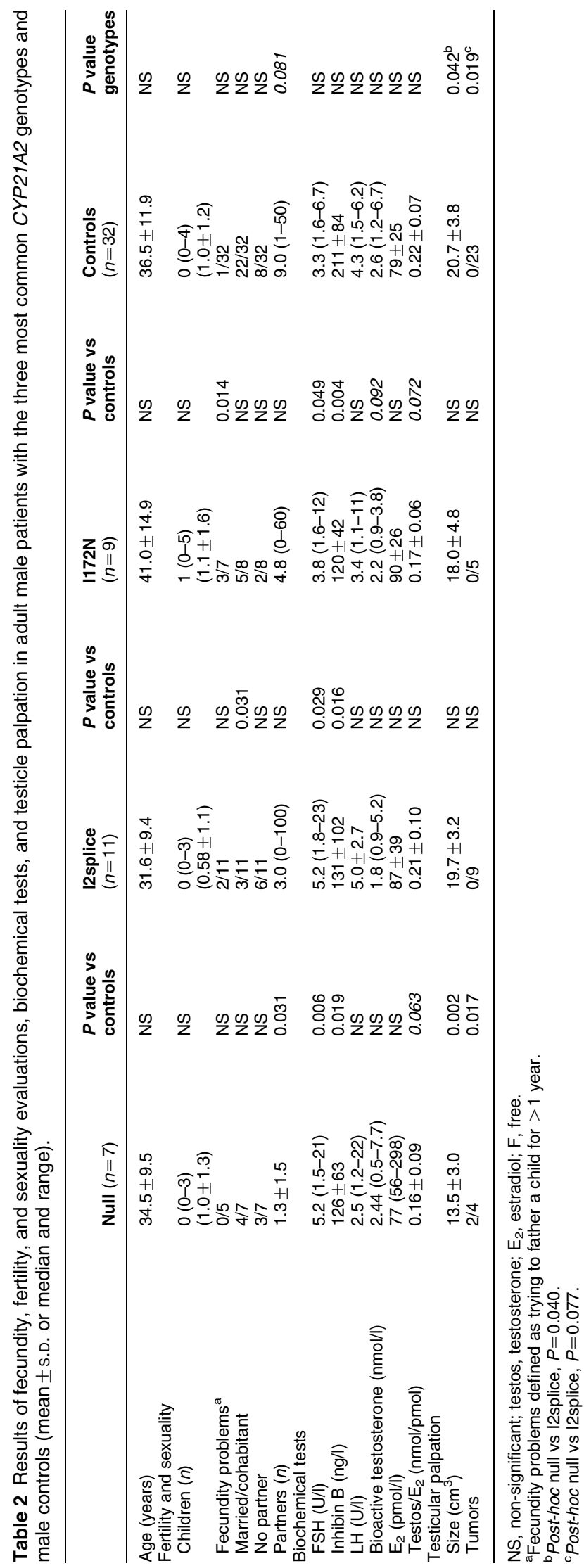

composition data and other markers for cardiovascular risk were compared in males with pathological and normal semen. Males with pathological semen had a higher truncal and total fat mass, total fat/lean mass ratio, and heart rate, in spite of similar $17 \mathrm{OHP}$ levels and corticosteroid doses (Table 4).

\section{Associations among TARTs, sperm number and quality, and the gonadotropin-gonadal steroid axis}

As shown in Fig. 2, total functional testicular volume was positively correlated with inhibin B levels and sperm concentration. There was also a trend to a positive association with sperm volume $(r=0.60$, $P=0.059$ ) and a significant positive correlation with the testosterone $/ \mathrm{E}_{2}$ ratio $(r=0.50, P=0.029)$. We also found the expected positive associations between inhibin B total functional testicular volume and the sperm count $(r=0.64, P=0.014)$ and concentration (Fig. 2) and with normal morphology $(r=0.48$, $P=0.061)$. FSH showed a negative correlation with sperm count $(r=-0.53, P=0.047)$ and concentration $(r=-0.70, P=0.004)$. The total TART volume tended to be negatively associated with height $(r=-0.44$, $P=0.056)$ and was positively correlated with $\mathrm{LH}$ $(r=0.41, P=0.046)$. There was no correlation with other hormones of the gonadotropin-testicular axis. No correlation was demonstrated between total TART volume or functional testicular volume and age, glucocorticoid dose, plasma renin, and ACTH concentrations (not shown).

\section{Male with 3 $\beta$-HSD type II deficiency}

The patient with $3 \beta$-HSD deficiency was 21 years old, had male external genitalia with a micropenis, lived alone, and had no children. On testicular palpation, bilateral multiple tumors were found and ultrasound showed a very small total functional volume $\left(1.9 \mathrm{~cm}^{3}\right)$ due to large bilateral TARTs measuring $25.6 \mathrm{~cm}^{3}$. A tumor measuring $2.4 \times 1.8 \times 1.5 \mathrm{~cm}$, with a weight of $3.2 \mathrm{~g}$, was extirpated. He had no sperm in the semen sample, but a testicular biopsy was able to retrieve $\sim 100$ severely abnormal sperms, which were saved for future ICSI. He had poor control with high DHEAS, and his FSH and LH were also high while inhibin B was low.

\section{Male with karyotype $46, X X$ and 21-hydroxylase deficiency}

The 46,XX CAH male was 61 years old and had a $4 \mathrm{~cm}$ phallos. He was diagnosed at age 7 when ovaries and a uterus had been found and was subsequently extirpated, following which he underwent glucocorticoid and testosterone replacement. He was married and had adopted two children. 


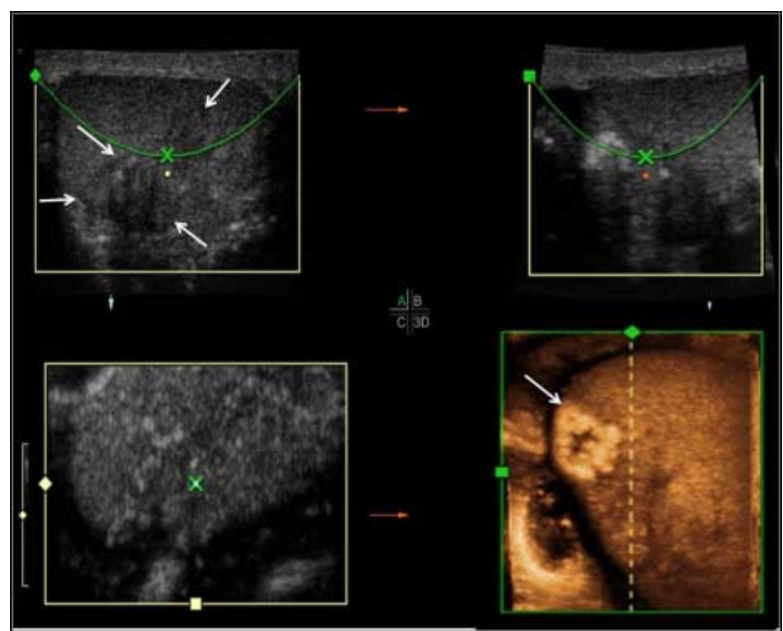

Figure 1 Illustration of the steps in the 3D inversion rendering process of right testicle of a 30-year-old male with $\mathrm{CAH}$ (genotype null/null) with two children. Acquisition in the three orthogonal planes and the rendered volume in the bottom right box. By eliminating the surrounding non-pertinent structures with the electronic scalpel, the structures of interest were left as the final inverted and rendered volume. In this case, it could be seen that the tumor was calcified and had a cystic structure (right bottom corner, the tumor marked with an arrow). In the left upper box, the tumor is marked with arrows (the size of the tumor was measured to be: $2.6 \times 1.1 \times 0.9 \mathrm{~cm}$, corresponding to a volume of $\left.1.4 \mathrm{~cm}^{3}\right)$. Full colour version of this figure available via http://dx.doi.org/10.1530/ EJE-11-0828.

\section{Discussion}

This study confirms that fertility is reduced in males with classic CAH. They also had fecundity problems more often than control men. TARTs were present in the majority of patients; hormonal evaluation demonstrated disturbed testicular function involving both Sertoli and Leydig cells, and in about half of the patients who had semen analysis performed, abnormal semen was found. Psychosocial and sexual issues were also investigated, but their impact on overall fertility rate appears modest.

The fertility rate was reduced by one half compared with national data and was impaired in all genotype groups associated with classic CAH. No obvious reason was found in the patients' social or sexual life. Although the patients were less experienced than controls in terms of number of sexual partners through life, the age at sexual debut, the rate of marriage/cohabitation, and the present coitus frequency were similar in patients and controls. More fecundity problems were reported, however, by the men in the I172N group. This may be due to metabolic factors (see below).

One reason for the decreased birth rate in females with $\mathrm{CAH}$ is increased homo- and bisexuality, with fewer individuals living in heterosexual relationships $(13,20)$. Among the male patients, none reported homo- or bisexuality. This is in keeping with the only previous report on sexual orientation studying nine CAH males (21).

Most likely, the predominant reason for reduced fertility is the frequent occurrence of TARTs, which were found in $86 \%$ of the examined patients, similar to the highest frequency reported previously (6). Others report prevalences of $0-67 \%$, which probably reflects differences in the mode of detection and age of the patients $(1,2,4,5,7,9,10,11,12)$. TARTs have been demonstrated in children at a frequency of slightly above $20 \%$ and found even in children 6 years of age $(22,23)$. Autopsy data have indicated TARTs in CAH boys of a few weeks of age (24).

We found TARTs in all genotype groups. Even both of our NC patients who had normal ACTH levels had small TARTs, which has previously been reported only with clearly elevated ACTH or angiotensin II (AII) (3). In contrast, a recent study found no case of TART in the I172N or the NC genotypes (9). Others have, however, also reported TARTs in $1172 \mathrm{~N}$ patients $(4,5,22)$, and in patients with SV (11). Another recent report found

Table 3 Testicular ultrasound exams and semen samples from adult patients with $\mathrm{CAH}$ and the three most common CYP21A2 genotypes (mean \pm S.D. or median and range).

\begin{tabular}{llllll}
\hline & Patients & Null & I2splice & I172N & $\begin{array}{l}\boldsymbol{P} \text { value } \\
\text { genotypes }\end{array}$ \\
\hline Ultrasound & $n=21$ & $n=4$ & $n=10$ & $n=4$ \\
$\quad$ Total volume $\left(\mathrm{cm}^{3}\right)$ & $22.7 \pm 7.5$ & $18.7 \pm 9.0$ & $24.6 \pm 6.0$ & $24.4 \pm 11.6$ & $\mathrm{NS}$ \\
TART present & $18 / 21$ & $4 / 4$ & $8 / 10$ & $4 / 4$ & $\mathrm{NS}$ \\
TART $(n)$ & $2.0(0-8)$ & $2.0(1-5)$ & $2(0-8)$ & $1.5(1-2)$ & $\mathrm{NS}$ \\
Total TART $\left(\mathrm{cm}^{3}\right)$ & $0.5(0-8.7)$ & $2.9(1.9-4.6)$ & $0.2(0-8.7)$ & $0.5(0.2-4.3)$ & 0.083 \\
Total functional $\left(\mathrm{cm}^{3}\right)$ & $20.4(7.1-36.7)$ & $15.6 \pm 8.1$ & $24.4 \pm 5.7$ & $23.0 \pm 9.8$ & $\mathrm{NS}$ \\
Semen sample & $n=14$ & $n=1$ & $n=6$ & $n=6$ & $\mathrm{NS}$ \\
Volume $(\mathrm{ml})$ & $2.3 \pm 0.6$ & 1.5 & $2.3 \pm 0.5$ & $2.2 \pm 0.6$ & $0.053^{\mathrm{a}}$ \\
Sperm count $\left(\times 10^{6}\right)$ & $151 \pm 112$ & 105 & $220 \pm 146$ & $88 \pm 19$ & $0.094^{\mathrm{a}}$ \\
Sperm conc. $\left(\times 10^{6} / \mathrm{ml}\right)$ & $70 \pm 54$ & 30 & $99 \pm 71$ & $44 \pm 18$ & $0.060^{\mathrm{a}}$ \\
Motile sperm $(\%)$ & $53 \pm 21$ & 1.0 & $64 \pm 11$ & $42 \pm 23$ & $\mathrm{NS}$ \\
Normal morphology $(\%)$ & $3.2 \pm 2.8$ & $1 / 1$ & $3.5 \pm 3.4$ & $2.2 \pm 1.9$ & $\mathrm{NS}$ \\
Pathological semen & $6 / 14$ & & $2 / 5$ & \\
\hline
\end{tabular}

NS, non-significant; TART, testicular adrenal rest tumor.

aOnly one male null/null patient provided a semen sample, thus comparisons were only performed between I2splice and I172N. 
Table 4 Patient characteristics and differences found in body composition, heart rate, blood pressure, and biochemical tests in adult $\mathrm{CAH}$ male patients with pathological and normal semen (mean \pm S.D. or median and range).

\begin{tabular}{llll}
\hline & $\begin{array}{l}\text { Pathological } \\
(n=6)\end{array}$ & $\begin{array}{l}\text { Normal } \\
(n=8)\end{array}$ & $\boldsymbol{P}$ value \\
\hline Age (years) & $40.3 \pm 15.1$ & $35.8 \pm 11.2$ & $\mathrm{NS}$ \\
Phenotype & $4 S W / 2 \mathrm{SV}$ & $4 \mathrm{SW} / 2 \mathrm{SV}$ & $\mathrm{NS}$ \\
$\mathrm{HCeq} / \mathrm{m}^{2}\left(\mathrm{mg} / \mathrm{m}^{2}\right)$ & $18.9 \pm 8.4$ & $15.4 \pm 2.2$ & $\mathrm{NS}$ \\
$\mathrm{BMI}\left(\mathrm{kg} / \mathrm{m}^{2}\right)$ & $29.4 \pm 6.3$ & $25.3 \pm 4.1$ & $\mathrm{NS}$ \\
Total fat mass $(\%)$ & $32.0 \pm 8.2$ & $24.3 \pm 5.7$ & 0.049 \\
Truncal fat mass $(\%)$ & $35.2 \pm 9.7$ & $25.9 \pm 7.0$ & 0.048 \\
Total fat/lean mass & $0.5 \pm 0.2$ & $0.3 \pm 0.1$ & 0.032 \\
24-h BP $(\mathrm{mmHg})$ & $134 \pm 6 / 79 \pm 5$ & $123 \pm 11 / 74 \pm 5$ & $0.062 / 0.099$ \\
24-h heart rate & $81 \pm 5$ & $73 \pm 5$ & 0.012 \\
Fecundity problems & $5 / 6$ & $0 / 8$ & 0.003 \\
FSH $>10(\mathrm{U} / \mathrm{l})$ & $2 / 6$ & $0 / 8$ & $\mathrm{NS}$ \\
Inhibin B $(\mathrm{ng} / \mathrm{l})$ & $157 \pm 57$ & $167 \pm 102$ & $\mathrm{NS}$ \\
Testosterone $(\mathrm{nmol})$ & $12.5 \pm 3.2$ & $17.8 \pm 6.2$ & 0.064 \\
Testos/E $(\mathrm{nmol} / \mathrm{pmol})$ & $0.17 \pm 0.04$ & $0.19 \pm 0.07$ & $\mathrm{NS}$ \\
S-TG (mmol/l) & $1.5 \pm 1.0$ & $0.9 \pm 0.3$ & 0.095 \\
\hline
\end{tabular}

NS, non-significant; HCeq, hydrocortisone equivalents; TG, triglyceride; BP blood pressure; testos/ $E_{2}$, testosterone/estradiol ratio.

${ }^{a}$ Fertility problems defined as attempting to father a child for $>1$ year.

TARTs exclusively in SW patients (12). The higher mean age of our patients compared with many of the previous studies may explain some of the differences. Only 10\% of TARTs were found by clinical examination in our cohort and it has been stated that usually only TARTs $>2 \mathrm{~cm}$ are detectable by palpation due to being buried within the testis (3). Consequently, all $\mathrm{CAH}$ males, including those with the milder pheno- and genotypes, should be examined periodically by testicular ultrasound and not only the classic ones.

It is alarming that two $(6.7 \%)$ of the $\mathrm{CAH}$ males had undergone testicular surgery for suspected malignancy with histology showing TARTs. Almost the same frequency of unnecessary testicular surgery for presumed malignancy has recently been reported from a large cohort of CAH males $(6.2 \%, 4 / 65)$ (10). Thus, an increased awareness and understanding of TARTs is needed.

There were associations in favor of a negative impact of TARTs on fertility. Total functional testicular volume was positively correlated with sperm parameters and inhibin B. Semen quality has recently been reported to be very poor in CAH males, with $100 \%$ being pathological if all the WHO criteria were considered (4). Our patients appeared less affected; using the same criteria, $43 \%$ of our CAH males had abnormal semen.

The results of several studies point to an increased likelihood of abnormal semen parameters among overweight men and obesity is associated with a higher incidence of male factor infertility (25). In large cohorts, decreased sperm quality was found already in overweight (BMI 25-30 kg/m²) compared with normal weight men (26). One of the proposed mechanisms is that increased estrogens due to aromatization of androgens in the adipose tissue can hamper fertility (25). Elevated fat mass is often found in $\mathrm{CAH}(27,28)$, and our $\mathrm{CAH}$ males with abnormal semen demonstrated increased total and abdominal body fat, and fat to lean mass ratio compared with $\mathrm{CAH}$ males with normal semen. Overall, our patients had a lower testosterone/ $\mathrm{E}_{2}$ ratio although the difference in these parameters between individuals with normal and pathological semen did not reach significance in the
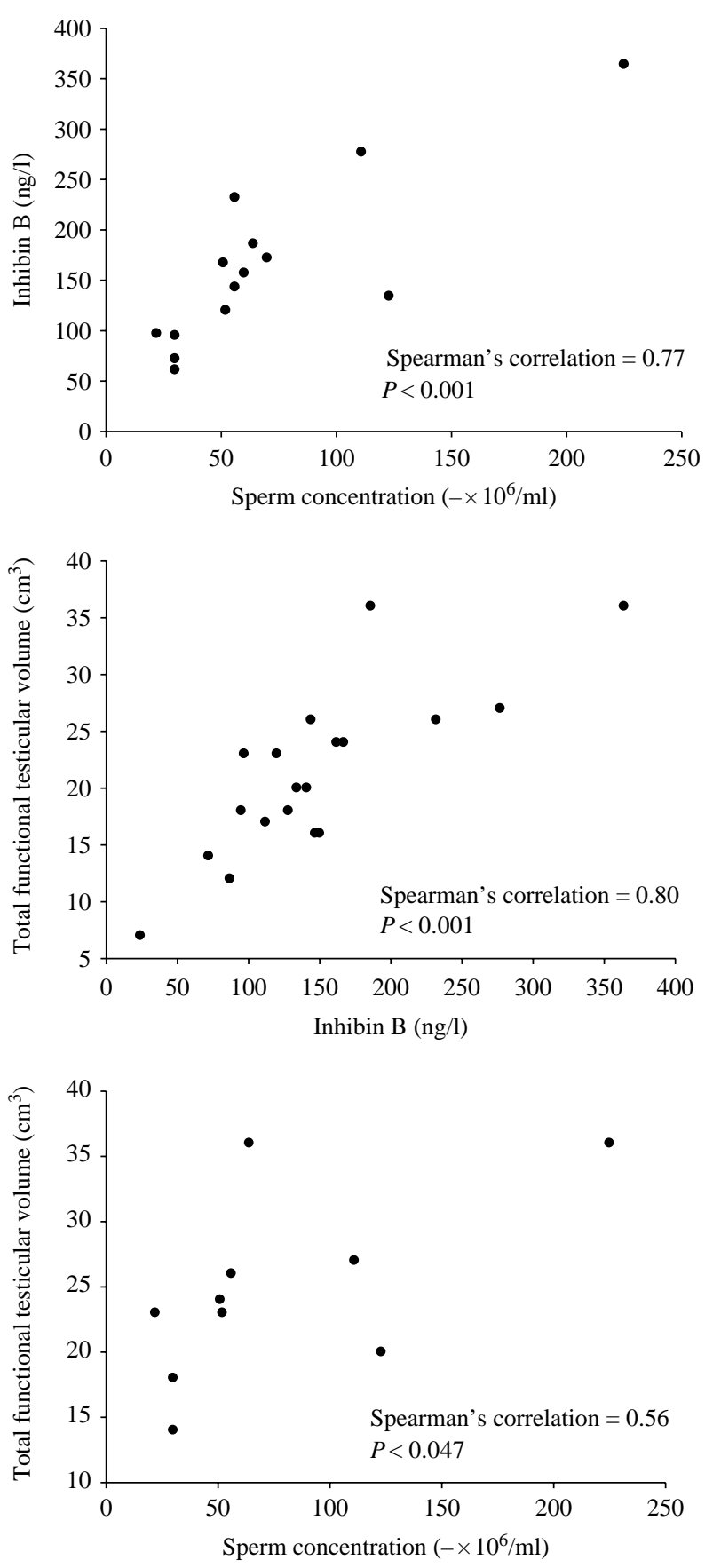

Figure 2 Correlation between inhibin B (upper panel), total functional testicular volume (lower panel) and sperm concentration, and total functional testicular volume and inhibin (middle panel) in adult males with $\mathrm{CAH}$ due to 21-hydroxylase deficiency. 
present small sample. The I172N genotype group tended to have a lower sperm quality compared with the I2splice patients, perhaps reflecting their previously reported negative cardiometabolic profile (15). Metabolic risk has been associated with decreased fertility and impaired sperm quality (29). None of the patients showed suppression of gonadotropins, which could be expected with extreme over- or undertreatment with glucocorticoids $(3,4)$.

Apart from conventional infertility treatment, there are few specific measures to offer CAH men with fertility problems. Weight loss may improve fertility in obese men (25) and normal weight should be aimed at. TARTs possess receptors for both ACTH and AII, and it has been hypothesized that high levels due to undertreatment with corticosteroids may enhance their growth (30). We found no correlation between TART volume and current ACTH or renin levels. However, subjects with large TARTs were shorter and had higher lean mass compared with those with no or very small TARTs. Almost $40 \%$ of patients with large TARTs had very high levels of urinary pregnanetriol and blood 17OHP, thereby indicating both poor control during adolescence and later. Increased glucocorticoid doses can reduce the size of the TARTs in the early stages, but continued growth is also seen when ACTH levels are suppressed. It remains unknown whether this is due to persistent stimulation via AII receptors or by other mechanisms as the effect of increased mineralocorticoid doses has not been systematically studied. Unfortunately, higher doses of glucocorticoids and mineralocorticoids will most certainly increase the frequency and severity of side effects $(10,15,28,31,32)$. In later stages, testicular surgery may sometimes be helpful, but in the end, when damage is irreversible, treatment options are very limited (3). Preservation of sperm could be considered before the TARTs have grown too much.

Fertility in 3 $\beta$-HSD deficiency has not been studied (33), but our patient was infertile with no sperm in his semen sample. Biopsy revealed a few severely affected sperms; ultrasound and surgery revealed virtually no functional testicular volume.

The major limitation of this study is its size despite being larger and including older $\mathrm{CAH}$ males than many other studies. Negative findings must therefore be interpreted with caution. Moreover, our controls had lower fertility than expected. Many of our patients did not collect a semen sample and a comparison with those who did indicated a selection bias as fecundity issues tended to be more prevalent in the latter group. Hence, those with problems appeared more motivated to produce a sample.

In conclusion, impaired fertility and fecundity were detected in adult men with CAH. Sexual and social issues appeared to have limited impact on fertility. The most obvious cause is the presence of TARTs, but other causes may contribute. Decreased semen quality was prevalent and those with pathological semen also had higher fat mass. The male with $3 \beta$-HSD deficiency was infertile. In spite of these findings, most males with $\mathrm{CAH}$ due to 21-hydroxylase deficiency who wish to be fathers seem to succeed eventually.

\section{Declaration of interest}

The authors declare that there is no conflict of interest that could be perceived as prejudicing the impartiality of the research reported.

\section{Funding}

This study was supported by the Magn. Bergvalls Foundation, Swedish Research Council (grant no. 12198 to A Wedell), Karolinska Institutet, Stockholm County Council and Göteborg Medical Society.

\section{Acknowledgements}

We thank Anette Härström RN, and Ingrid Hansson RN, for excellent care of the patients and controls. We also thank Professor Martin E Ritzén for his valuable advice.

\section{References}

1 Urban MD, Lee PA \& Migeon C. Adult height and fertility in men with congenital virilizing adrenal hyperplasia. New England Journal of Medicine 1978299 1392-1396. (doi:10.1056/ NEJM197812212992505)

2 Jääskeläinen J, Kiekara $\mathrm{O}$, Hippeläinen $\mathrm{M}$ \& Voutilainen R. Pituitary gonadal axis and child rate in males with classical 21-hydroxylase deficiency. Journal of Endocrinological Investigation $20002323-27$.

3 Claahsen-van der Grinten HL, Otten BJ, Stikkelbroeck MM, Sweep FC \& Hermus AR. Testicular adrenal rest tumours in congenital adrenal hyperplasia. Best Practice and Research. Clinical Endocrinology and Metabolism 200923 209-220. (doi:10.1016/j. beem.2008.09.007)

4 Reisch N, Flade L, Scherr M, Rottenkolber M, Pedrosa Gil F, Bidlingmaier M, Wolff H, Schwarz HP, Quinkler M, Beuschlein F \& Reincke M. High prevalence of reduced fecundity in men with congenital adrenal hyperplasia. Journal of Clinical Endocrinology and Metabolism 200994 1665-1670. (doi:10.1210/jc.2008-1414)

5 Cabrera MS, Vogiatzi MG \& New MI. Long term outcome in adult males with classic congenital adrenal hyperplasia. Journal of Clinical Endocrinology and Metabolism 200186 3070-3078. (doi:10.1210/jc.86.7.3070)

6 Stikkelbroeck NM, Otten BJ, Pasic A, Jager GJ, Sweep CG, Noordam K \& Hermus AR. High prevalence of testicular adrenal rest tumors, impaired spermatogenesis, and Leydig cell failure in adolescent and adult males with congenital adrenal hyperplasia. Journal of Clinical Endocrinology and Metabolism 200186 5721-5728. (doi:10.1210/jc.86.12.5721)

7 Avila NA, Premkumar A, Shawker TH, Jones JV, Laue L \& Cutler GB Jr. Testicular adrenal rest tissue in congenital adrenal hyperplasia: findings at gray-scale and color Doppler US. Radiology 1996198 99-104.

8 Avila NA, Premkumar A \& Merke DP. Testicular adrenal rest tissue in congenital adrenal hyperplasia: comparison of MR imaging and sonographic findings. AJR. American Journal of Roentgenology 1999 172 1003-1006.

9 Mouritsen A, Jørgensen N, Main KM, Schwartz M \& Juul A. Testicular adrenal rest tumours in boys, adolescents and adult men with congenital adrenal hyperplasia may be associated with the CYP21A2 mutation. International Journal of Andrology 2010 33 521-527. (doi:10.1111/j.1365-2605.2009.00967.x) 
10 Arlt W, Willis DS, Wild SH, Krone N, Doherty EJ, Hahner S, Han TS, Carroll PV, Conway GS, Rees DA, Stimson RH, Walker BR, Connell JM, Ross RJ \& the United Kingdom Congenital Adrenal Hyperplasia Adult Study Executive (CaHASE). Health status of adults with congenital adrenal hyperplasia: a cohort study of 203 patients. Journal of Clinical Endocrinology and Metabolism 201095 5110-5121. (doi:10.1210/jc.2010-0917)

11 Kang MJ, Kim JH, Lee SH, Lee YA, Shin CH \& Yang SW. The prevalence of testicular adrenal rest tumors and associated factors in postpubertal patients with congenital adrenal hyperplasia caused by 21-hydroxylase deficiency. Endocrine Journal 201158 501-508. (doi:10.1507/endocrj.K11E-034)

12 Nermoen I, Rørvik J, Holmedal SH, Hykkerud DL, Fougner KJ, Svartberg J, Husebye ES \& Løvås K. High frequency of adrenal myelolipomas and testicular adrenal rest tumours in adult Norwegian patients with classical congenital adrenal hyperplasia due to 21-hydroxylase deficiency. Clinical Endocrinology 201175 753-759. (doi:10.1111/j.1365-2265.2011.04151.x)

13 Hagenfeldt K, Janson PO, Holmdahl G, Falhammar H, Filipsson H, Frisén L, Thorén M \& Nordenskjöld A. Fertility and pregnancy outcome in women with congenital adrenal hyperplasia due to 21-hydroxylase deficiency. Human Reproduction 200823 1607-1613. (doi:10.1093/humrep/den118)

14 SCB. Generation statistics from Statistics Sweden (SCB). Available from www.scb.se/statistik/_publikationer/BE9999_2005A01_BR _BE96ST0605.pdf (accessed July 2011), 2005.

15 Falhammar H, Filipsson Nyström H, Wedell A \& Thorén M. Cardiovascular risk, metabolic profile, and body composition in adult males with congenital adrenal hyperplasia due to 21-hydroxylase deficiency. European Journal of Endocrinology 2011164 285-293. (doi:10.1530/EJE-10-0877)

16 Taskinen S, Taavitsainen M \& Wikström S. Measurement of testicular volume: comparison of 3 different methods. Journal of Urology 1996155 930-933. (doi:10.1016/S0022-5347(01) 66349-3)

17 World Health Organization. WHO Laboratory Manual for the Examination of Human Semen and Sperm-Cervical Mucus Interaction, 4th edn. Cambridge, United Kingdom: Cambridge University Press, 1999.

18 Vermeulen A, Verdonck L \& Kaufman JM. A critical evaluation of simple methods for the estimation of free testosterone in serum. Journal of Clinical Endocrinology and Metabolism $1999 \mathbf{8 4}$ 3666-3672. (doi:10.1210/jc.84.10.3666)

19 Liddle GW. Clinical pharmacology of anti-inflammatory steroids. Clinical Pharmacology and Therapeutics 19612 615-635.

20 Frisén L, Nordenström A, Falhammar H, Filipsson H, Holmdahl G, Janson PO, Thorén M, Hagenfeldt K, Möller A \& Nordenskjöld A. Gender role behavior, sexuality, and psychosocial adaptation in women with congenital adrenal hyperplasia due to CYP21A2 deficiency. Journal of Clinical Endocrinology and Metabolism 2009 94 3432-3439. (doi:10.1210/jc.2009-0636)

21 Hines M, Brook C \& Conway GS. Androgen and psychosexual development: core gender identity, sexual orientation and recalled childhood gender role behavior in women and men with congenital adrenal hyperplasia (CAH). Journal of Sex Research 200441 75-81. (doi:10.1080/00224490409552215)

22 Claahsen-van der Grinten HL, Sweep FC, Blickman JG, Hermus AR \& Otten BJ. Prevalence of testicular adrenal rest tumours in male children with congenital adrenal hyperplasia due to 21-hydroxylase deficiency. European Journal of Endocrinology $2007 \mathbf{1 5 7}$ 339-344. (doi:10.1530/EJE-07-0201)

23 Martinez-Aguayo A, Rocha A, Rojas N, García C, Parra R, Lagos M, Valdivia L, Poggi H, Cattani A \& Chilean Collaborative Testicular Adrenal Rest Tumor Study Group. Testicular adrenal rest tumors and Leydig and Sertoli cell function in boys with classical congenital adrenal hyperplasia. Journal of Clinical Endocrinology and Metabolism 200792 4583-4589. (doi:10. 1210/jc.2007-0383)

24 Shanklin DR, Richardson AP Jr \& Rothstein G. Testicular hilar nodules in adrenogenital syndrome. The nature of the nodules. American Journal of Diseases of Children 1963106 243-250.

25 Du Plessis SS, Cabler S, McAlister DA, Sabanegh E \& Agarwal A. The effect of obesity on sperm disorders and male infertility. Nature Reviews. Urology 20107 153-161. (doi:10.1038/nrurol.2010.6)

26 Hammoud AO, Wilde N, Gibson M, Parks A, Carrell DT \& Meikle AW. Male obesity and alteration in sperm parameters. Fertility and Sterility 200890 2222-2225. (doi:10.1016/ j.fertnstert.2007.10.011)

27 Mooij CF, Kroese JM, Claahsen-van der Grinten HL, Tack CJ \& Hermus AR. Unfavourable trends in cardiovascular and metabolic risk in paediatric and adult patients with congenital adrenal hyperplasia? Clinical Endocrinology 201073 137-146. (doi:10.1111/j.1365-2265.2009.03690)

28 Falhammar H, Filipsson H, Holmdahl G, Janson PO, Nordenskjöld A, Hagenfeldt K \& Thorén M. Metabolic profile and body composition in adult women with congenital adrenal hyperplasia due to 21-hydroxylase deficiency. Journal of Clinical Endocrinology and Metabolism 200792 110-116. (doi:10.1210/ jc.2006-1350)

29 Kasturi SS, Tannir J \& Brannigan RE. The metabolic syndrome and male infertility. Journal of Andrology 200829 251-259. (doi:10. 2164/jandrol.107.003731)

30 Claahsen-van der Grinten HL, Otten BJ, Sweep FC, Span PN, Ross HA, Meuleman EJ \& Hermus AR. Testicular tumors in patients with congenital adrenal hyperplasia due to 21-hydroxylase deficiency show functional features of adrenocortical tissue. Journal of Clinical Endocrinology and Metabolism 200792 3674-3680. (doi:10.1210/jc.2007-0337)

31 Falhammar H, Filipsson H, Holmdahl G, Janson PO, Nordenskjöld A, Hagenfeldt K \& Thorén M. Fractures and bone mineral density in adult women with 21-hydroxylase deficiency. Journal of Clinical Endocrinology and Metabolism $2007 \mathbf{9 2}$ 4643-4649. (doi:10.1210/jc.2007-0744)

32 Falhammar H, Filipsson H, Holmdahl G, Janson PO, Nordenskjöld A, Hagenfeldt K \& Thorén M. Increased liver enzymes in adult women with congenital adrenal hyperplasia due to 21-hydroxylase deficiency. Endocrine Journal 200956 601-608. (doi:10.1507/endocrj.K08E-312)

33 Pang S. Congenital adrenal hyperplasia owing to 3 betahydroxysteroid dehydrogenase deficiency. Endocrinology and Metabolism Clinics of North America 200130 81-99. (doi:10. 1016/S0889-8529(08)70020-3)

Received 22 September 2011

Revised version received 1 December 2011

Accepted 8 December 2011 